\title{
IMPRESSÃO 3D NA CULTURA DO DESIGN CONTEMPORÂNEO
}

\author{
Natal Anacleto Chicca Junior \\ Universidade Federal do Ceará ${ }^{1}$ \\ natal@virtual.ufc.br
}

Prof. Leonardo Gómez Castillo, Ph.D

Universidade Federal de Pernambuco

leonardo.a.gomez@gmail.com

\begin{abstract}
Resumo: Apesar de não ser uma tecnologia tão recente, até há pouco tempo, as impressoras tridimensionais ficavam restritas às grandes indústrias pelo seu custo muito elevado. A constante redução de preços aliada à crescente variedade de modelos, alguns com valores cada vez mais acessíveis, está proporcionando um aumento em sua aquisição, não apenas por empresas, mas também por consumidores entusiastas em conhecer esta ferramenta. Em virtude do maior consumo de equipamentos, está ocorrendo um aumento progressivo em seu número de usuários e eventual difusão dos equipamentos em diferentes países e, consequentemente, a formação de comunidades virtuais sobre impressão 3D. O emprego destes dispositivos pode não apenas transformar a forma como os objetos são criados, mas também a maneira que são produzidos e consumidos. Um dos grandes diferenciais é conseguir reproduzir com eficiência produtos, impressos individualmente, com o mesmo acabamento das grandes fábricas. Assim sendo, a impressão tridimensional altera a forma como os objetos são criados e também ocasiona mudanças em relação à produção e ao consumo de produtos. Eliminar a necessidade de estoques e reduzir gastos com transportes são possíveis consequências da mudança dos meios de produção. A transformação das mídias físicas em digitais e o processo de compartilhamento de arquivos pela internet estão evoluindo e se tornando mais simplificados, permitindo democratizar a informação e, através de comunidades virtuais, poder cooperar, trocar e modificar projetos construindo um conhecimento coletivo. A possibilidade de criar um único produto com acabamento industrial, aliado ao conceito de projeto colaborativo e a movimentos como o do Design Livre, representa uma mudança não apenas na execução de um determinado projeto, mas também na relação entre as pessoas e os artefatos. Desta forma, o artigo pretende apresentar a impressora 3D como ferramenta de transformação da cultura material e suas eventuais implicações, desafios e
\end{abstract}

${ }^{1}$ Doutorando do Programa de Pós-Graduação em Design da Universidade Federal do Pernambuco (UFPE). 
oportunidades associadas aos paradigmas do design de produto contemporâneo.

Palavras-chave: cultura material, cibercultura, Design Livre e impressão 3D.

\begin{abstract}
Despite not be a recent technology, until recently, the threedimensional printers were restricted to large industries because their very high cost. The constant reduction in prices combined with growing variety of models, some with very accessible values, is providing an increase in its acquisition, not only for companies, but also for enthusiastic consumers who wants to know this tool. Due to growing consumption of equipment, it is gradually increasing its number of users and eventual dissemination of equipment through different countries and, consequently, the formation of virtual communities on 3D printing. The use of these devices cannot only transform the way objects are created, but also the way they are produced and consumed. A major differential is able to reproduce efficiently products, individually printed, with the same finishing of large factories. Therefore, the dimensional printing changes the way objects are created and also causes changes related to production and consumption of products. Eliminate the need for inventory and reduce transport expenses are possible consequences of changing the means of production. The transformation from physical to digital media and the file sharing process by internet are evolving and becoming more simplified, allowing to democratize information and, through virtual communities, to cooperate, exchange and modify projects building a collective knowledge. The ability to create a unique product with industrial finishing allied to the concept of collaborative design and movements such as the Open Design represents a change not only in the execution of a particular project, but also in the relationship between people and artifacts. Thus, the paper aims to present the 3D printer as a tool of transformation of material culture and its implications, challenges and opportunities associated with the paradigms of contemporary product design.
\end{abstract}

Keywords: material culture, cyberculture, Open Design and 3D printing.

\title{
1. INTRODUÇÃO
}

O processo de fabricação de uma peça de vestuário era muito trabalhoso até o início do século XVIII. Na confecção de um sapato, por exemplo, um artesão tinha que cortar e costurar cada parte manualmente. A produção de um produto como este demorava dias. Algumas décadas depois, na Inglaterra, a fabricação se tornou mais ágil com a introdução das máquinas de corte e costura operadas manualmente. Foi o início da primeira Revolução Industrial e o trabalho puramente manual começou a ser mecanizado com máquinas a vapor. Graças à mudança do processo de produção, o sapato ficou mais acessível, porém ainda custava caro. Em meados do século XIX, a produção fabril estava ainda mais eficiente, os equipamentos a vapor estavam sendo substituídos com a invenção de máquinas movidas a eletricidade. $E$, no início do século 
XX, nos Estados Unidos, o empresário Henry Ford utilizou tais máquinas em conjunto com as primeiras linhas de produção. Assim como acontecia com os carros de Ford, milhares de sapatos também passaram a ser fabricados simultaneamente, em tempo recorde, e finalmente reduzindo o seu custo. Essa automação da produção em massa em grandes fábricas se tornou o símbolo da segunda Revolução Industrial.

Agora, no início do século XXI, uma nova transformação se anuncia. Autores como Gershenfeld $(2005)^{2}$, Rifkin (2011) ${ }^{3}$, Anderson (2012), e Troxler (2013) anunciam uma terceira Revolução Industrial. Ao longo dos anos, as máquinas a vapor foram substituídas pelas movidas a eletricidade e agora estão dando lugar a máquinas digitais, conectadas a internet. Uma das grandes características desta nova revolução é que as ferramentas de produção já não precisam de grandes investimentos de capital. Desta forma, facilita o surgimento de novos produtores que incorporam a figura do "proprietário-fabricante", característica semelhante aos artesãos por acumular funções. Anderson (2012) complementa que a tecnologia das impressoras tridimensionais pode transformar a criação dos objetos, mudando não apenas a forma como eles são criados, mas também a maneira que são produzidos e consumidos.

O presente trabalho aborda algumas mudanças que estão acontecendo com os equipamentos de produção material ao se tornarem financeiramente mais acessíveis e as suas eventuais consequências para a indústria. A seguir, uma visão do impacto sociocultural ao introduzir o conceito de personalização em massa alterando as atuais linhas de produção de produtos padronizados. Logo depois, uma breve explicação do funcionamento e algumas características das impressoras 3D seguido do conceito de imaterialidade das mídias e alguns de seus desdobramentos. Posteriormente, um apanhado sobre criação colaborativa e movimentos como o Design Livre, além das características da cibercultura, que influenciam as relações de produção e consumo de artefatos. E por fim, uma breve explicação, algumas características e eventuais transformações nos paradigmas do design contemporâneo.

\section{DESENVOLVIMENTO}

Os avanços tecnológicos acontecem de forma contínua. Nos anos 1980, o computador foi inserido como ferramenta de trabalho e os designers passaram a utilizar seus programas para realizar diversas tarefas, antes feitas à mão. Trinta anos atrás, ninguém poderia imaginar a impressão de um livro fora de uma gráfica profissional. Hoje, as impressoras à laser e o manuseio das fontes, dos layouts de páginas e das técnicas de revisão, que eram detidas por profissionais especializados, estão banalizadas. Isso começa a ocorrer no mundo da produção material devido à aquisição individual de dispositivos, como as impressoras em três dimensões e as máquinas de corte a laser, com um nível crescente de acabamento e recursos que estão se diversificando a cada dia.

Consequentemente, a relação de mercado existente entre o inventor e o empreendedor está se modificando, pois conceber algo não exige mais necessariamente submeter sua ideia a um empresário fabricante para que o invento possa se concretizar. Para Ricardo Abramovay (2012), um dos grandes diferenciais

${ }^{2}$ GERSHENFELD, Neil A. Fab: the coming revolution on your desktop - from personal computers to personal fabrication. New York: Basic Books, 2005.

3 RIFKIN, Jeremy. The third industrial revolution. How lateral power is transforming energy, the economy, and the world. New York: Palgrave Macmillan, 2011. 
desta nova revolução industrial é a possibilidade individual de conceber e fabricar com eficiência bens que, até recentemente, só podiam sair de grandes fábricas.

"Assim como a internet mudou, redistribuiu e acelerou a difusão da informação, essa tecnologia pode transformar a fabricação de produtos de algo rígido e dependente de capital num processo flexível, baseado em criatividade." (BARIFOUSE; CORONATO; CISCATI, 2012).

Portanto, está se estabelecendo uma nova relação entre quem concebe o produto e o consumidor. A terceira revolução altera o processo de fabricação, com a introdução das impressoras 3D, permitindo que cada artefato produzido seja feita de acordo com o gosto pessoal e a necessidade de cada consumidor e até pelo próprio consumidor. "É o surgimento da manufatura pessoal", diz Abe Reichental, presidente da 3D Systems, um dos maiores fabricantes de impressoras 3D do mundo (apud ABRAMOVAY, 2012).

\subsection{0 impacto sociocultural}

Para Barifouse, Coronato e Ciscati (2012), a mudança do processo de fabricação de produtos seguindo o gosto pessoal e a necessidade de cada consumidor e com um grau de acabamento similar ao de grandes fábricas é considerado como uma "personalização em massa". Isso abre oportunidades para que empreendedores, inventores e até mesmo indústrias possam lançar novos produtos sem se preocupar com vendas em grande escala para torná-los economicamente viáveis. Desta forma, sugere mudanças na sociedade, em relação a produção e ao consumo de produtos, e avalia possíveis impactos em relação a cultura material. O termo cultura material é utilizado no sentido de promover uma compreensão maior do papel dos artefatos em um mundo em que o consumo de mercadorias constitui um fenômeno de importância social e cultural.

Contudo, a cultura, por possuir uma condição ampla, pode ser definida tanto como "material", traduzida em artefatos e tecnologia mas também como "imaterial", produto da atividade psíquica seja nos aspectos cognitivos quanto nos afetivos, incorporando significados, valores e normas. Considerando que além de um papel utilitário, os objetos trazem em si uma carga simbólica, pois além de possuir cor, textura, matéria-prima, forma e função; têm história e contexto cultural. Desta maneira, mesmo a cultura sendo convencionalmente dividida em material e imaterial é preciso reforçar que a separação não existe de fato e a sua única justificativa reside em necessidades metodológicas. Portanto, ao analisar a "personalização em massa" em relação a definição de cultura, se destaca a possibilidade de criar produtos singulares e que representam ao usuário o retorno do poder, antes perdido pelo processo de padronização industrial, de expressão do indivíduo.

Além disso, ao ter a demanda reduzida a escalas menores de produção, aumenta as chances de alcançar o objetivo, evidenciado por Bonsiepe (1997), em conquistar a satisfação da sociedade e, desta forma, seus resultados podem se caracterizar como uma inovação sociocultural.

\subsection{0 processo de impressão 3D}

O processo de impressão 3D funciona de forma similar a uma impressora convencional que muitas pessoas têm em casa. Basta apertar o botão na tela do 
computador para que o arquivo digital, com o desenho em três dimensões do objeto a ser fabricado, seja enviado para a impressora. A partir de um programa computacional o arquivo tridimensional é dividido digitalmente em milhares de camadas de até 0,1 milímetro e envia uma série de instruções para a impressora. Em vez de tinta, ela usa materiais como plástico, gesso, silicone, borracha ou metais, para fazer diversos objetos tais como: próteses dentárias, joias, luminárias, brinquedos, peças de equipamentos hospitalares e até mesmo sapatos.

No processo conhecido como síntese aditiva, a produção começa pela base do objeto. O cartucho deposita uma fina camada do material utilizado para impressão sobre uma plataforma. Uma vez formada essa camada inicial, a impressora aplica outra camada sobre a primeira. $O$ processo se repete com a acúmulo de várias camadas até o objeto ficar pronto e o seu tempo de impressão varia de acordo com o tamanho e a complexidade do modelo.

Outra característica do processo é que ao invés de fabricar cada parte de um produto separadamente e depois montá-las, é possível imprimir todas as peças já agrupadas. Além de reduzir a quantidade de peças na montagem de um determinado produto, ainda reduz a necessidade do envio de cada uma de suas partes através de diversos fabricantes em diferentes partes do mundo economizando tempo, matériaprima e também dinheiro.

\subsection{A imaterialidade das mídias}

A Sociedade da Informação, movimento iniciado com os primeiros computadores pessoais surgidos nos anos 1970 e que, para Anderson (2006), mais importante que os aparelhos, a grande contribuição para o usuário final foram os programas e sistemas derivados dela. Entre eles, a internet que se popularizou ao longo das décadas de 1980 e 1990, e que continua em expansão com a comunicação móvel e sem fio, difundida através de dispositivos móveis e computadores portáteis. “(...) não é mais necessário que nos movimentemos em direção à rede, ela já nos envolve em um ambiente de conexão que, cada vez mais, se generaliza." (COSTA, 2009, p.171). A autora (ibid., 2009) aponta que tal impacto afeta as práticas sociais, alterando a forma que o indivíduo produz, difunde e consome informação e bens culturais, passando por novas possibilidades de emergência de expressões culturais.

A palavra artefato se refere especificamente aos objetos produzidos pelo trabalho humano, em oposição aos objetos naturais ou acidentais. Contudo, da mesma forma como acontece com o indivíduo, os artefatos também estão sofrendo mudanças, assim como seus respectivos processos de produção que já não são necessariamente realizados através de objetos físicos. A imaterialidade das mídias está sendo responsável pela mudança no modo de produzir e consumir e alguns artefatos já são produzidos pela manipulação de bits e bytes. Os arquivos digitais utilizados nas impressoras 3D podem ser criados a partir de programas de modelagem digital ou podem ser encontrados em sites como o Thingiverse, o Instructables ou o Shapeways ${ }^{4}$ que reúnem uma grande quantidade de modelos e usuários interessados em realizar downloads e/ou uploads de modelos tridimensionais. Os artefatos que antes eram

\footnotetext{
${ }^{4}$ Os endereços dos sites são respectivamente: <http://www.thingiverse.com/>, < http://www.instructables.com/> e $<$ http://www.shapeways.com/>.
} 
físicos estão sendo substituídos paulatinamente pelos digitais, reduzindo a necessidade de fabricação de objetos tais como livros, CDs, DVDs, causando alterações nos modos de produção e modificando as relações de consumo, seja para o entretenimento ou ambientes de trabalho. A mudança e consequente difusão é obtida graças ao avanço de alguns aspectos tecnológicos como: maior velocidade na transmissão de dados e comodidade dos serviços oferecidos online, aumento no consumo e maior capacidade de recursos nos dispositivos móveis, armazenamento de dados através da computação em nuvem, entre outros fatores. "As novas tecnologias incorporaram ao nosso cotidiano novas formas de comunicar, de consumir e ter acesso, de produzir e de distribuir. Isso vale para produtos, serviços, informação, conhecimento e cultura." (COSTA, 2009, p.180).

Os artefatos digitais estão substituindo os físicos e se movendo pelo mundo em quantidades (e variedades) cada vez maiores. Os arquivos voltados a impressão podem se materializar fisicamente através de qualquer impressora 3D desde que siga seus parâmetros de produção. Assim como a internet eliminou as distâncias e as barreiras para a informação, as impressoras 3D estão começando a eliminar as do mundo material. Do mesmo modo que um arquivo pode ser enviado pelo correio eletrônico como "PDF" (portable document format) e posteriormente ser impresso em 2D, um artefato pode ser enviado através de um arquivo "STL" (stereolithography) instantaneamente para qualquer parte do mundo via internet e ser impresso em 3D. Uma das possíveis implicações desta nova forma de produção é eliminar a necessidade de estoques de peças sobressalentes podendo imprimir de acordo com a necessidade de troca ou de reparo. A produção e a distribuição poderão ser descentralizadas de determinados países, como a China por exemplo, e diminuir os gastos com transporte entre outros custos, como os referentes a importação, além da possibilidade de customização de cada impressão sem representar custo adicional.

\subsection{A criação colaborativa e o movimento Design Livre}

Anderson (2006) acredita que a internet não apenas facilitou o acesso à informação, como também democratizou a criação e a distribuição de conteúdo. 0 trabalho online colaborativo, como os programas com o código aberto, apresenta um novo formato de criação e de compartilhamento de inteligência no desenvolvimento de programas de computadores. Trata-se de recombinações de linhas de códigos de forma aberta, livre e criativa, construindo um dos mais interessantes fenômenos da cibercultura. A base e o objetivo da inteligência coletiva é o reconhecimento e o enriquecimento mútuo das pessoas: "é a inteligência distribuída por toda parte, incessantemente valorizada, coordenada em tempo real, que resulta em uma mobilização efetiva das competências." (LÉVY, 1998, p.28). O conceito se baseia no fato de que ninguém sabe tudo, de que todos sabem alguma coisa e de que a inteligência individual não existe: "ela é sempre fruto do que aprendemos em experiências e interações anteriores com outros indivíduos e inteligências". (COSTA, 2009, p.174).

"O homem (...) é um herdeiro de um longo processo acumulativo, que se reflete o conhecimento e a experiência adquirida pelas numerosas gerações que 0 antecederam. A manipulação adequada e criativa desse patrimônio cultural permite as inovações e as invenções" (LARAIA, 1986, p.45). O processo de produção através da 
impressora 3D, permite estabelecer novas relações do usuário com o seu produto, similar à forma que Pierre Lévy (1998) caracteriza a informação na cibercultura, transformando os envolvidos em emissores e receptores, produtores e consumidores da mensagem. André Lemos comenta, em seu artigo "Cibercultura, cultura e identidade"5: "A cibercultura está pondo em sinergia processos de cooperação, de troca e de modificação criativa de obras, dadas as características da tecnologia digital em rede (...) Ao instaurar uma cultura planetária de troca e de cooperação, estaria resgatando o que há de mais rico na dinâmica de qualquer cultura." Logo, a internet não ajudou apenas a romper as barreiras geográficas, como também facilitou a reunião de pessoas em comunidades, através de redes sociais, auxiliando a promover discussões e desenvolver elementos em comum, construindo conhecimento coletivo através da troca de informações.

Para Abramovay (2012), criar, reproduzir e distribuir informação, cultura, arte e ciência são hoje atividades que os dispositivos da sociedade da informação em rede colocam nas mãos das pessoas. "O lema punk aqui passa a ser: faça você mesmo os seus programas, colabore, compartilhe e modifique códigos de forma a quebrar a hegemonia dos softwares proprietários" (LEMOS, 2010). Contudo, a discussão não é sobre software, mas sim hardware. De forma semelhante as comunidades de software de código aberto, os produtos criados, modificados e distribuídos de maneira colaborativa são chamados de "open source hardware" e Troxler (2013) esclarece que tal movimento não é, de forma alguma, um novo fenômeno e já vem sendo documentado desde os séculos XVIII e XIX. O autor comenta a importância do movimento e que, graças a algumas pesquisas da época, determinadas tecnologias (que se tornaram a chave para o movimento de industrialização) foram possíveis de se tornar realidade graças ao processo de invenção colaborativa. Contudo, Troxler (2013) acha irônico medir a quantidade de inovação de um determinado país através de seu número de patentes e inclusive as aponta como um dos grandes obstáculos ao desenvolvimento da tecnologia que, segundo sua evolução ao longo da história, sempre foi livre. $O$ open source hardware se baseia, assim como também acontece nas comunidades livres de programas para computador, em cinco características comuns: liberdade para estudar, usar, redistribuir, modificar e compartilhar os frutos de suas modificações. O compartilhamento da informação permite que a tecnologia evolua muito mais rápido que o normal. Para Anderson (2012), do mesmo modo que a internet facilitou o acesso, criação e distribuição de conteúdo, o mesmo está acontecendo com a fabricação de artefatos. Como, por exemplo, o movimento maker (criador), formado por entusiastas em fabricação pessoal, interessados em produzir suas próprias coisas.

O Design também conta com um movimento colaborativo chamado de "Open Design". No Brasil, o termo ficou conhecido como Design Livre e consiste em um sistema distribuído de design baseado em compartilhamento, colaboração, licenças abertas, projetos abertos (e distribuídos), tecnologias de fabricação abertas (e distribuídas). Ele deve ser considerado mais do que apenas uma nova maneira de criar produtos e segundo o trecho do livro "Design Livre" ${ }^{\text {, }}$ o termo representa um processo

${ }^{5}$ http://www.portalseer.ufba.br/index.php/contemporaneaposcom/article/viewFile/3416/2486

${ }^{6}$ Disponível em http://designlivre.org/download/ 
colaborativo orientado à inovação aberta. O próprio livro considera a definição como pleonasmo pois, segundo o mesmo, todo processo de design é colaborativo. Ele reforça que o Design Livre é aberto, como todo design, já que não há maneira de ocultar o design em sua totalidade e, de outra maneira, ele não seria consumido, acessado, tocado, usado. No entanto, o que pode ser escondido é justamente a maneira de fazê-lo. O seu foco, portanto, não é apenas que o produto do processo de design seja disponibilizado de forma colaborativa, mas todo o processo de elaboração. Logo, o Design Livre chega a ser considerado um processo e uma cultura, que também muda as relações entre as pessoas com o fazer, com o usar e com o cuidar das coisas.

\subsection{Os "novos" paradigmas do design}

Assim como estão acontecendo mudanças nas relações de produção e consumo de artefatos, ocasionando fenômenos como, por exemplo, a desmaterialização das mídias, o design também está passando por transformações. Thackara (2005) evidencia a necessidade de mudança de paradigma quanto ao design: de "projetar para" substituindo por "projetar com" e do "design como um projeto" para o "design como um serviço", implicando em modelos de ação colaborativos, contínuos e abertos, que incluam o usuário.

O autor reforça a importância da integração do designer com agentes locais e cidadãos para desenvolver formas de inovação colaborativa, que resultam em novos serviços para a vida cotidiana das comunidades. "(...)a maioria das soluções envolvem novas alianças e novas conexões e, neste sentido, aponta-se a necessidade de desenvolver visão periférica e cultivar o habito de observar pessoas, lugares, organizações, projetos e ideias em busca de novas ligações e oportunidades." (THACKARA, 2005, p.216).

Acredita-se que o próximo passo é alinhar a produção de artefatos, a partir de impressoras 3D, com os conceitos apresentados por Mont (2000): "um sistema de produtos, serviços, redes de suporte e infraestrutura desenvolvidos para ser competitivo, satisfazer as necessidades dos usuários e apresentar impacto ambiental menor que os modelos de negócio tradicionais". Segundo Krucken (2008), a inovação estratégica desta abordagem é uma nova interpretação do conceito de produto. A concepção de produto já não é o resultado de um processo de produção industrial, e evoluiu para um conjunto integrado de produtos e serviços, mutuamente dependentes e orientados a uma dada necessidade.

Deste modo, não basta repensar formas de produzir ou consumir artefatos, as considerações, levantadas no parágrafo anterior, sinalizam os desafios e as oportunidades do design no desenvolvimento de soluções sistêmicas (incluindo produtos, serviços e informações), reafirmando a necessidade de repensar a cultura e a pratica do projeto e também as formas de intervenção do design na sociedade.

O compromisso de assumir tais paradigmas se faz cada vez mais necessário à profissão do designer e soa como uma preocupação real no cenário atual, entretanto, "novos" conforme destacado neste título ganha destaque, uma vez que, é oportuno ressaltar que o papel do design no "universo dos serviços" e na "troca de informações, transcendendo a atividade tradicional de projeto formal e físico dos objetos", já havia sido antecipado por Branzi (1988, p. 13) na década de 1980. 


\section{CONCLUSÃO}

O emprego das impressoras 3D na produção de bens de consumo vai além das inovações tecnológicas que o computador trouxe à era industrial e isso se exprime em três mudanças decisivas: a criação de bens materiais torna-se acessível a indivíduos; as mais promissoras inovações vêm de projetos colaborativos entre seus usuários, através das redes sociais; e o poder sobre o que é oferecido aos consumidores está cada vez menos nas mãos daqueles que detêm os grandes meios de produção.

A inovação tecnológica que o computador trouxe, desconcentrando a fabricação de bens materiais apenas pela indústria, tem um grande impacto ao tornar a produção acessível aos indivíduos. A capacidade de poder produzir algo, ao invés de comprá-lo, muda a relação usuário-objeto.

Os objetos têm funcionado, em todos os tempos, como elementos de diferenciação social e/ ou de sociabilização dos indivíduos. Qualquer objeto é fruto da criação intelectual e do trabalho criativo do ser humano, no entanto, projetistas poderão ter uma liberdade maior de criação ao se desvincular das limitações de empresários fabricantes. A relação de um produto com o seu usuário pode ser mais próxima ao reduzir, ou até mesmo eliminar, as interferências e demandas do mercado no diálogo entre designer (projetista) $x$ empresa (cliente para o qual ele projeta) $x$ usuário (quem vai realmente utilizar o produto). Em alguns casos, o projeto será desenvolvido pelo próprio usuário permitindo customização individual em produtos já existentes ou criação de artefatos voltados para finalidades cada vez mais específicas. Deste modo, permite ao usuário ter opções de produtos diferenciados da padronização seriada imposta pela linha de produção da indústria.

As redes sociais terão papel fundamental na troca de informações e os usuários das comunidades serão responsáveis pelo caráter colaborativo ao poder criar, trocar, modificar e compartilhar soluções de artefatos com um crescente grupo de pensadores, projetistas e consultores, espalhados por todo o mundo, dedicados as mais diversas questões projetuais. Lembrando que o designer não estará mais focado apenas no produto, mas na solução de um determinado problema de modo a satisfazer as necessidades dos usuários. Com isso, evidencia-se a importância em repensar a cultura e a prática do projeto e também as formas de intervenção do design na sociedade, características já apontadas por alguns métodos projetuais tais como o design thinking.

No entanto, ainda é difícil prever quais serão as reais transformações a longo prazo do fenômeno da fabricação pessoal, que Anderson (2012) chama de "nova revolução industrial", o qual "os átomos são os novos bits". Apesar do crescimento da produção individualizada, muito do que está sendo discutido no artigo ainda são previsões e isso não significa, por exemplo, que a produção em massa vai simplesmente desaparecer. Contudo, algumas mudanças já estão acontecendo. Hoje, a impressão 3D já estimula a criação de novos formatos e outros modificados de produção, alterando a cultura contemporânea, gerando novas formas de consumo de bens culturais, novos formatos de produção de bens simbólicos, novas visões sobre propriedade e autoria, personalização e massificação. Da mesma forma, que a internet aboliu a passividade do usuário, transformando o agente que antes era apenas um receptor para um emissor-receptor, e fez da interação e da mistura (remix) a base da 
cultura contemporânea; essa nova revolução industrial pode fazer da colaboração social em rede o principal fundamento da criação de riqueza das sociedades atuais.

Outros temas relevantes como o papel do designer nessa revolução, a caracterização do processo criativo-colaborativo em relação a métodos e ferramentas, e o ensino dessas novas habilidades e competências dentro dos cursos de design serão investigados e abordados na tese de doutoramento que está sendo realizada pelo primeiro autor deste artigo.

\section{REFERÊNCIAS}

ABRAMOVAY, Ricardo. O movimento dos fazedores e o espírito do faça você mesmo. 2012. Em: <http://www1.folha.uol.com.br/empreendedorsocial/colunas/1190457-omovimento-dos-fazedores-e-o-espirito-do-faca-voce-mesmo.shtml> Acesso em: 08 junho 2013.

ANDERSON, Chris. A Cauda Longa: do Mercado de massa para o mercado de nicho. Rio de Janeiro: Ed. Campus, 2006.

ANDERSON, Chris. Makers. A nova revolução industrial. Rio de Janeiro: Editora Campus, 2012.

BARIFOUSE, Rafael; CORONATO, Marcos; CISCATI, Rafael. A nova revolução industrial muda a forma como os objetos são criados, produzidos e consumidos. 2012. Em: <http://revistaepoca.globo.com/Ciencia-e-tecnologia/noticia/2012/10/novarevolucao-industrial-muda-forma-como-os-objetos-sao-criados-produzidos-econsumidos.html> Acesso em: 12 maio 2013.

BONSIEPE, G. Design, do material ao digital. Florianópolis: FIESC/IEL, 1997.

BRANZI, A. Pomeriggi alla media industria. Milan: Idea Books, 1988.

COSTA, Eliane. Impacto das tecnologias na produção, na distribuição e no consumo culturais. In: Economia da cultura: ideias e vivências. Rio de Janeiro: Publit, 2009.

KRUCKEN, Lia. Competências para o design na sociedade contemporânea. Cadernos de Estudo Avançado em Design, Caderno 2, v. 1 (jul. 2008). Editora Santa Clara: Belo Horizonte, 2008.

LARAIA, Roque de Barros. Cultura. Um conceito antropológico. Rio de Janeiro: Jorge Zahar Ed., 1986.

LEMOS, André. Cibercultura punk. Revista Cult. n.96, março de 2010.

LÉVY, Pierre. A inteligência coletiva: por uma antropologia do ciberespaço. São Paulo: Edições Loyola, 1998.

MONT, O. Product-Service Systems. Stockholm, Swedish EPA, AFR-report 288:83, 2000.

THACKARA, J. In the bubble: designing in a complex world. Cambridge: MIT, 2005.

TROXLER, Peter. Making the 3rd Industrial Revolution. The Struggle for Polycentric Structures and a New Peer- Production Commons in the Fab Lab Community. In: Fablab: Of Machines, Makers, and Inventors (Cultural and Media Studies). Bielefeld: Transcript Publishers, 2013. 